\title{
Indoor radon concentration measurements at the site of the first nuclear power plant in Egypt
}

\author{
A.S. Hussein ${ }^{\mathrm{a}}$ \\ Naif Arab University for Security Sciences, Riyadh, KSA. \\ Nuclear Power Plants Authority, Cairo, Egypt.
}

Received 8 December 2013 - Accepted 24 March 2014

\begin{abstract}
Radon $\left({ }^{222} \mathrm{Rn}\right)$ is a radioactive gas that occurs naturally when uranium in soil and rock breaks down. Longterm exposure to ${ }^{222} \mathrm{Rn}$ increases the risk of lung cancer. The principal objective of this work was to determine the ${ }^{222} \mathrm{Rn}$ activity concentration in an indoor air environment at the El-Dabaa site proposed for a nuclear power plant project in Egypt using the track etch technique with LR115 detectors. The annual average indoor ${ }^{222} \mathrm{Rn}$ activity concentration in apartment buildings varies from 24 to $77 \mathrm{~Bq} \cdot \mathrm{m}^{-3}$, with a mean value of $54 \mathrm{~Bq} \cdot \mathrm{m}^{-3}$. The annual effective dose received by residents of the studied area was estimated to be $0.41 \mathrm{mSv}$. The annual estimated effective dose is less than the recommended action level by ICRP $\left(3-10 \mathrm{mSv}^{-1} \mathrm{y}^{-1}\right)$. The results from this work provide a radiological assessment program and update the background of the natural radioactivity map at the El-Dabaa site.
\end{abstract}

Keywords: Radon / environmental samples / El-Dabaa / LR115 detectors / nuclear power

\section{Introduction}

The first Egyptian nuclear power plant was proposed to be built at the El-Dabaa site. The El-Dabaa site is located on the Mediterranean sea coast of the western desert and is about $400 \mathrm{~km}$ from Cairo and about $150 \mathrm{~km}$ west of Alexandria. The site is about $15 \mathrm{~km}$ long and $3-4 \mathrm{~km}$ wide, as shown in Figure 1.

The Nuclear Power Plants Authority (NPPA) has set up an environmental laboratory at this site to conduct the preoperational environmental radiological monitoring program for the El-Dabaa area. This program provides a baseline map of natural and man-made radioactivity background levels in all exposure pathways in the El-Dabaa area. This map will be used as reference information to assess any changes in radioactivity background levels due to the operation of the future nuclear power plant on this site (EL-Daly and Hussein, 2008). The current measurements deal with the ambient gamma dose rate, gross low alpha and low beta emitters, gamma ray spectroscopy with $\mathrm{NaI}(\mathrm{Tl})$ and HPGe detectors, alpha spectrometry, and water chemical analysis (EL-Daly and Hussein, 2008; IAEA, 2000). As part of this program, radon activity concentration measurements are carried out in indoor air using LR115 alpha track detectors with the cup technique. LR115 detectors have high sensitivity, low cost, are easy to handle and retain a permanent record of the data. Also, these detectors incorporate the effects of seasonal and diurnal fluctuation of radon activity concentrations due to physical and geological factors as well as meteorological factors (Durrani and Ilic, 1997). Radon and its

\footnotetext{
a drahmedsaad860@gmail.com
}

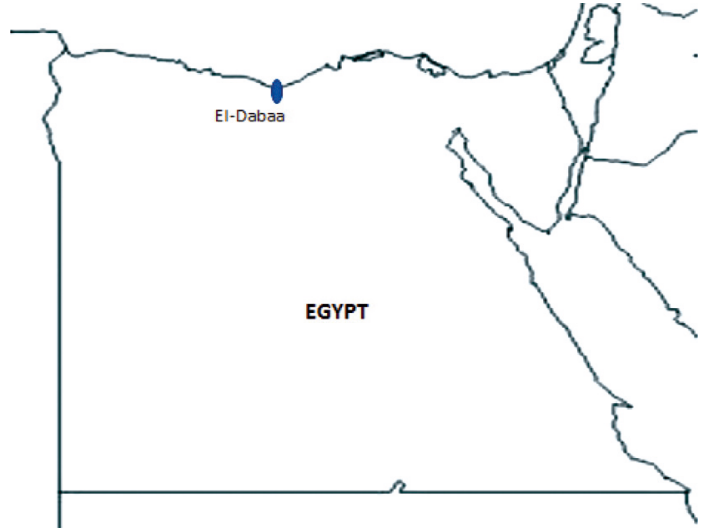

Fig. 1. Location of the El-Dabaa site.

decay products, called radon daughters or radon progeny, emit highly ionizing alpha radiation. Radon has been classified as a human carcinogen. Since environmental radon on average accounts for about a half of all human exposure to radiation from natural sources, as shown in Figure 2 (UNSCEAR, 2000). Increasing attention has been paid to exposure to radon and its associated health risks in both industrialized and developing countries (WHO, 2009).

During recent years, numerous papers have appeared in the literature demonstrating the interest in monitoring radon in indoor environments in Egypt (Hafez et al., 2000a, 2000b; Hafez and Husein, 2001; Hussein, 2002, 2006; Hafez et al., 2003; Abu El-Ela et al., 2004; El-Bahi, 2004; Gomma et al., 2004; Abdel-Ghany, 2005; Abo-Elmagd et al., 2007; Abd El-Zaher, 2011). 


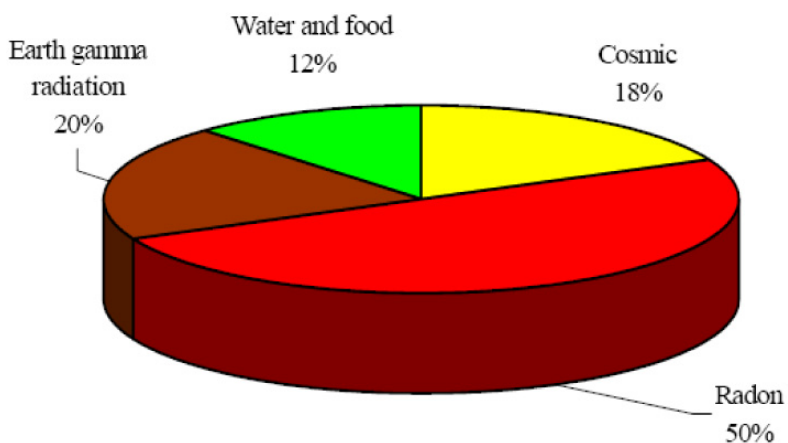

Fig. 2. Sources and average distribution of natural background radiation for the world's population (UNSCEAR, 2000).

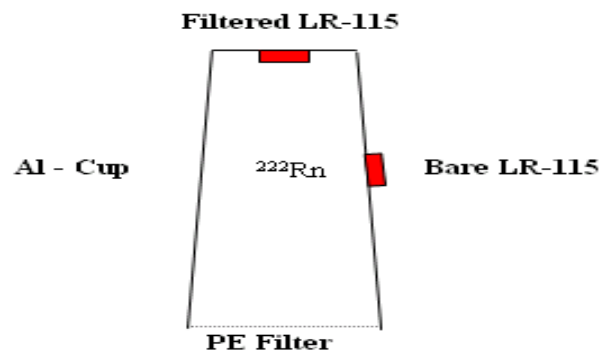

Fig. 3. Schematic diagram of the passive radon device (Durrani and Ilic, 1997).

The aim of the present work is to determine the radon activity concentrations in indoor air in the El-Dabaa area, as well as radon health effects.

\section{Materials and methods}

The radon measuring device was a diffusion cup with internal (filtered) and external (bare) LR115 detectors as shown in Figure 3 (Durrani and Ilic, 1997).

This device can be used for simultaneous estimation of the radon activity concentration $(C)$ and the equilibrium factor $(F)$ between radon and its progeny. Four measuring devices were deployed inside each measured building. Most of the buildings in the surveyed area are concrete buildings and built using cement, sand, bricks, marble and concrete as the construction materials, and are all one-floor buildings. In every measuring location, the devices were hung about $2.5 \mathrm{~m}$ from the ground in bedrooms and living rooms (two cups in each). The period of the survey was during 2007-2010, covering all seasons. The exposed LR115 detectors were chemically etched in $\mathrm{NaOH}$ solution under standard conditions $\left(2.5 \mathrm{M}\right.$ at $60{ }^{\circ} \mathrm{C}$ for $2 \mathrm{~h}$ ) and the track density measurements were made using an optical microscope of magnification of 100× (Durrani and Ilic, 1997).

The track density recorded on the internal (filtered) detector $\rho_{i}$ is related to the radon activity concentration $C\left(\mathrm{~Bq} \cdot \mathrm{m}^{-3}\right)$ by (Somogy, 1990; Planinić et al., 1997):

$$
C=\frac{\rho_{i}}{K \eta t}
$$

where $K$ is the attenuation coefficient of radon, $\eta$ is the radon calibration factor in tracks $\mathrm{cm}^{-2}$ per Bq. $\mathrm{m}^{-3}$ per day and $t$ is the exposure time.
The equilibrium factor $F$ between radon and its progeny was calculated using the following empirical formula (Frank and Benton, 1997; Somogy, 1990):

$$
F=a R-b
$$

where $a$ and $b$ are fitting parameters, $R=K \frac{\rho_{e}}{\rho_{i}}, 1.2<R \leqslant 3$ and $\rho_{\mathrm{e}}$ is the track density recorded on the external (bare) detector. Recently the values of the above-mentioned fitting parameters were found to be $a=0.5$ and $b=0.53$ as given by Planinić et al. (1997). Substituting the value of the slope of the regression line between the track densities of LR115 detectors $\left(\rho_{e}\right.$ and $\rho_{i}$ ) in equation (2), the equilibrium factor $F$ could be calculated.

The effective dose $(E)$ was calculated using conventions published in ICRP Publication 65 (1993) by the following equation:

$$
E=C T\left(\varepsilon_{\mathrm{r}}+\varepsilon_{\mathrm{d}} K F\right),
$$

where $K=1.6 \times 10^{-6}$ WLM per Bq.h.m ${ }^{-3}, T$ is the occupancy time in hours, $m$ and $\varepsilon_{\mathrm{r}}=0.74 \times 10^{-7} \mathrm{mSv} \cdot \mathrm{h}^{-1}$ per Bq. $\mathrm{m}^{-3}$ and $\varepsilon_{\mathrm{d}}=5 \mathrm{mSv}$ per WLM for work are the conversion factors for radon free progeny and radon daughters, respectively.

The effective dose could also be calculated by using the formula given in UNSCEAR (1993):

$$
E=C T\left(\varepsilon_{\mathrm{r}}+\varepsilon_{\mathrm{d}} F\right),
$$

where $\varepsilon_{\mathrm{r}}=0.17 \mathrm{nSv} \cdot \mathrm{h}^{-1}$ per Bq.m ${ }^{-3}$ and $\varepsilon_{\mathrm{d}}=$ $9 \mathrm{nSv} \cdot \mathrm{h}^{-1}$ per Bq. $\mathrm{m}^{-3}$.

\section{Results and discussion}

The calibration coefficient $\eta$ for the LR-115 detectors obtained from the calibration experiment was $0.036 \pm 0.006 \alpha$ tracks $\mathrm{cm}^{-2} \cdot \mathrm{d}^{-1}$ per Bq. $\mathrm{m}^{-3}$ of radon (Hussein, 2002). This value was used to estimate the radon activity concentration $C$ with the help of equation (1). From the measured track densities $\rho_{i}$ and $\rho_{e}$ and using equation (2), the equilibrium factor $F$ was calculated. Using equations (3) and (4) the effective dose values were calculated based on the yearly mean value of both the radon activity concentration and equilibrium factor inside the studied buildings. In this study it was assumed that the occupancy factors were 0.62 for houses and 0.2 for workplaces.

The results for the annual indoor radon concentration $C$, the annual equilibrium factor $F$ and the annual effective dose $E$ are shown in Table 1.

It is clear that ${ }^{222} \mathrm{Rn}$ activity concentrations in the indoor air of the studied areas are below the action levels stipulated by ICRP Publication 65 (1993): 200-600 Bq. ${ }^{-3}$ for dwellings and $200-1000 \mathrm{~Bq} \cdot \mathrm{m}^{-3}$ for workplaces, except in the simulator room which was found to be within this level. It is a closed room with a bad ventilation system. All estimated doses were found to be less than the lower bound of the action levels $\left(3-10 \mathrm{mSv} \cdot \mathrm{y}^{-1}\right)$ recommended by ICRP Publication 65 (1993). It is observed that the site area is safe as far the health hazard effects are concerned.

Table 2 shows the comparison of results obtained from this study with other Egyptian studies of radon activity concentrations in indoor air using the same technique. It is clear from Table 2 that ${ }^{222} \mathrm{Rn}$ activity concentrations in indoor air of the 
Table 1. Yearly average radon activity concentration $(C)$, equilibrium factor $(F)$ and effective dose $(E)$ in indoor air at the El-Dabaa site.

\begin{tabular}{lcccccc}
\hline \multirow{2}{*}{ Location } & \multicolumn{2}{c}{$\boldsymbol{C}\left(\mathbf{B q} \cdot \mathbf{m}^{-\mathbf{3}}\right)$} & & $\boldsymbol{F}$ & \multicolumn{2}{c}{$\boldsymbol{E}\left(\mathbf{m S v} \cdot \mathbf{y}^{-\mathbf{1}}\right)$} \\
\cline { 2 - 7 } & Ave. & Range & Ave. & Range & $\begin{array}{c}\text { ICRP } \\
\text { UNSCEAR } \\
(\mathbf{1 9 9 3})\end{array}$ \\
\hline Apartment Buildings & 54 & $24-77$ & 0.20 & $0.12-0.32$ & 0.41 & 0.47 \\
Environmental Lab. & 80 & $53-137$ & 0.23 & $0.10-0.43$ & 0.23 & 0.27 \\
Training Center: & & & & & & \\
- Simulator room & 480 & $156-570$ & 0.12 & $0.1-0.15$ & 0.69 & 0.90 \\
- Lecture rooms & 42 & $32-70$ & 0.20 & $0.15-0.29$ & 0.11 & 0.11 \\
\hline
\end{tabular}

Table 2. Comparison of radon activity concentrations in indoor air with other studies in Egypt.

\begin{tabular}{lcc}
\hline The studied area & $\boldsymbol{C}\left(\mathbf{B q} \cdot \mathbf{m}^{-3}\right)$ & Reference \\
\hline El-Dabaa site & $54(24-77)$ & This study \\
Alexandria City & $65 \pm 10$ & Abd El-Zaher, 2011 \\
Qena City & $40(19-59)$ & Hussein, 2006 \\
Mansura City & $170(43-423)$ & Abu El-Ela et al., 2004 \\
Cairo City & $47.94-84.32$ & Abdel-Ghany, 2005 \\
\hline
\end{tabular}

studied area were found to be consistent with data obtained by other authors, and it is in a low background radiation area in Egypt.

\section{Conclusion}

In this study, an attempt was made to obtain an overview of the ${ }^{222} \mathrm{Rn}$ activity concentrations in indoor air environments in the El-Dabaa area. These measurements were made using LR115 etched track detectors with the cup technique. The measured values of ${ }^{222} \mathrm{Rn}$ activity concentrations in indoor air reflect a low background radiation area in Egypt. In the near future it is planned to expand our study to different environmental samples (air, water, soil) at the El-Dabaa site as well as the new proposed sites for nuclear power plants in Egypt.

\section{References}

Abd El-Zaher M. (2011) Seasonal variation of Indoor Radon concentration in dwellings of Alexandria City, Egypt, Radiat. Prot. Dosim. 143 (1), 56-62.

Abdel-Ghany H.A. (2005) Variability of radon concentrations in different compartments of dwellings in Egypt, Medical Journal of Islamic World Academy of Sciences 15, 153-156.

Abo-Elmagd M., Metwally S.M., El-Fiki S.A., Eissa H.M., Salama E. (2007) Passive and active measurements of radon-related parameters inside ancient Egyptian tombs in Luxer, Radiat. Meas. 42, 116-120.

Abu El-Ela A., Hafez A.F., Othman M., El-Farrash A.H. (2004) Study of radon levels in some closed area in Mansoura City, Egypt. In: Proceedings of the Environmental Physics Conference, 24-28 Feb. 2004, Minya, Egypt.

Durrani S.A., Ilic R. (1997) Radon Measurements by Etched Track Detectors. World Scientific, Singapore.

El-Bahi S.M. (2004) Assessment of radioactivity and radon exhalation rate in Egyptian cement, Health Phys. 86 (5), 517-522.
EL-Daly T.A., Hussein A.S. (2008) Natural radioactivity levels in environmental samples in north western desert of Egypt. In: 3rd Environmental Physics Conference, 19-23 Feb. 2008, Aswan, Egypt.

Frank A.L., Benton E.V. (1997) Radon dosimetry using plastic nuclear track detectors, Nucl. Track Detection 1, 149-179.

Gomaa M.A., Hussein A.S., El-Arabi A.M. (2004) Radon measurements in Egypt using passive etched track detectors: a review. In: Seventh Conference of Radiation Physics and Protection, 27-30 Nov. 2004, Ismaelia, Egypt.

Hafez A.F., Hussein A.S., Rasheed N.M. (2000a) Radon measurements in underground metro stations in Cairo city, Egypt. In: Seventh Conference of Nuclear Sciences and Applications, Cairo, Egypt, 6-10 February, 2000.

Hafez A.F., Hussein A.S., Rasheed N.M. (2000b) A study of radon and thoron release from Egyptian building materials using polymeric nuclear track detectors, Appl. Radiat. Isotopes 54, 291-298.

Hafez A.F., Hussein A.S. (2001) Radon activity concentrations and effective doses in ancient Egyptian tombs of the Valley of the Kings, Appl. Radiat. Isotopes 54, 355-362.

Hafez A.F., Bishara A.A., Kotb M.A., Hussein A.S. (2003) Regular radon activity concentration and effective dose measurements inside the Great Pyramid with passive nuclear track detectors, Health Phys. 85 (2), 210-216.

Hussein A.S. (2002) Measurements of environmental alpha - activity using CR-39 and LR-115 plastic nuclear track detectors, $\mathrm{PhD}$ thesis, Alexandria University.

Hussein A.S. (2006) Radon concentrations in some Egyptian dwellings using LR115 detectors. In: Eighth Conference of Radiation Physics and Protection, 12-17 Nov. 2006, Bani Sueif, Egypt.

IAEA (2000) Environmental and source monitoring for purpose of radiation protection, IAEA Safety Guide No Rs-G-1.8.

ICRP Publication 65 (1993) International Commission on Radiological Protection, Protection Against Radon-222 at Home and at Work. Pergamon Press, Oxford.

Planinić J., Radolic V., Faj B., Varga Z. (1997) Radon equilibrium factor and aerosol, Nucl. Instrum. Meth. A, 396, 414-417.

Somogy G. (1990) The environmental behavior of radium, Technical Report Series No. 310, Vol. 1 Chaps. 3-8, International Atomic Energy Agency.

UNSCEAR (1993) United Nations Scientific Committee on the Effects of Atomic Radiation, Sources and effects of ionizing radiation, United Nations, New York.

UNSCEAR (2000) Sources and Effects of Ionizing Radiation, Report to the general Assembly, United Nations, New York.

WHO (2009) Handbook on Indoor Radon: A public Health Perspective. World Health Organization Press. 